\title{
Práticas teatrais e o ensino de Ciências: o teatro jornal na abordagem da temática do lixo
}

\section{Theatrical practices and science education: the newspaper theater in approach to the thematic of garbage}

\author{
Nívia Magalhães da Silva Freitas* \\ Terezinha Valim Oliver Gonçalves**
}

\begin{abstract}
RESUMO
A interlocução entre Ciência e Arte, especialmente pela mediação do teatro, constitui-se perspectiva potencializadora do ensino de Ciências. O teatro, para além do entretenimento e da diversão, possibilita ações reflexivas, formativas e educativas. A pesquisa configurou-se como qualitativa, na modalidade narrativa. Buscamos nos conduzir pela seguinte questão de pesquisa: em que termos, experiências formativas, mediadas por práticas teatrais, contribuem para a aprendizagem de conhecimentos socialmente relevantes e compreensão crítica e reflexiva da realidade? Para fins deste artigo, selecionamos o telejornal intitulado "Diálogo Noturno", o qual foi submetido à análise textual discursiva. A experiência do teatro jornal levou à constituição de espaços de (re)criação, de vivências estéticas, de resgate do modo como se aprende (e como se ensina), em um processo dialético que favoreceu a compreensão da realidade ambiental. A perspectiva de renovação do ensino de ciências, com o uso da arte pela ciência e a arte como forma de ampliar a compreensão da ciência no mundo, nos leva a ponderar que, ao vincularmos pensamento crítico às possiblidades de um fazer criativo, como no teatro, tem-se a constituição de "produtos" que auxiliam o fazer educativo para a formação de cidadãos críticos.
\end{abstract}

Palavras-chave: Práticas teatrais. Ensino de Ciências. Formação de professores.

${ }^{*}$ Universidade Federal do Pará. Faculdade de Ciências Naturais. Breves, Pará, Brasil. E-mail: nivia.bio2015@gmail.com. http://orcid.org/0000-0002-6838-478X

** Universidade Federal do Pará. Instituto de Educação Matemática e Científica. Belém, Pará, Brasil. E-mail: tevalim@yahoo.com.br. http://orcid.org/0000-0001-8285-3274 


\begin{abstract}
The interlocution between Science and Art, especially through the mediation of the theater, constitutes a potential perspective of science education. The theater, in addition to entertainment and fun, enables reflective, formative and educational actions. The research was configured as qualitative, in the narrative modality. The study was conducted to answer the following research question: in what terms formative experiences, mediated by theatrical practices, contribute to the learning of socially relevant knowledge and critical and reflective understanding of reality? For purposes of this article, we analyze the TV news program entitled "Dialogue Night", which was submitted to textual discourse analysis. The experience of the newspaper theatre led to constitution of (re) creation spaces, aesthetic experiences and apprehension of how you learn (and how it also teaches) in a dialectical process, that favored the understanding of the reality that surrounds us. The renewal perspective of science education, through the use of art for science and art as a way to enlarge the understanding of science in the world, leads us to consider that by connecting critical thought to the possibilities of a creative perform in the theater, there is formation of "products" that help the educational process for the preparation of critical citizens.
\end{abstract}

Keywords: Theatrical practices. Science education. Teacher training.

\title{
Sinopse
}

Ciência e Arte, campos aparentemente distintos, aproximam-se, visto que apresentam interpretações similares a respeito do funcionamento do universo, "[...] apenas representam-no com linguagens diferentes" (REIS; GUERRA; BRAGA, 2006, p. 72). A história da ciência e da arte têm seguido caminhos similares (SPINELI; PINHEIRO, 2011). Para Ianni (2004, p. 11), são “[ [...] muitos, em todo o mundo, os que reconhecem que as ciências e as artes se encontram e se fertilizam contínua e reiteradamente".

Corroborando com essa ideia, Klisys (2010, p. 13) afirma que a Ciência e a Arte "[...] são espaços de possibilidades, investigação, autoria, autonomia, construção de conhecimentos e subjetividade". Assim, no presente trabalho, buscamos nos conduzir pela seguinte questão de pesquisa: em que termos experiências formativas, mediadas por práticas teatrais, contribuem para a aprendizagem de conhecimentos socialmente relevantes e compreensão crítica e reflexiva da realidade? $\mathrm{Na}$ apresentação deste artigo, notadamente na desig- 
nação das suas seções, inclusive na introdução deste trabalho, fizemos uso de elementos afeitos ao teatro.

\section{Primeiro ato: conhecendo as relações entre Ciência e Arte - o teatro como ponto de inflexão}

Pertencentes a campos distintos, com características peculiares que as singularizam, a Ciência (campo científico) e a Arte (campo artístico) buscam, respectivamente, explicações, representações e interpretações da realidade. Embora com suas singularidades, os campos científico e artístico também apresentam similitudes, notadamente no que diz respeito aos seus intentos de desvelar e revelar o mundo (SANTOS; RIGOLIN, 2011), bem como de compreendê-lo em suas múltiplas relações.

Cachapuz (2014) afirma que tem sido um desafio por em prática a concepção interdisciplinar entre Arte e Ciência, mais precisamente no contexto da Educação em Ciências. Segundo o autor, isso se deve à própria ideia de interdisciplinaridade veiculada, ou seja, a interdisciplinaridade pretendida é construída apenas com base nos conhecimentos disciplinares e que tem deixado de lado saberes não disciplinares oriundos de outros campos.

Os desafios são reais, mas acreditamos que a prática teatral, voltada para a sala de aula, pode se constituir em instrumento de transformação do ensino que ainda se configura como memorístico, transmutando-o para aquele que possa ser capaz de tocar o sujeito, no sentido de que ele possa refletir e se posicionar sobre questões cotidianas e científicas relevantes para a sociedade em que vive. Nesse ponto, reiteramos as palavras de Klisys (2010, p. 105), na compreensão de que "[...] tantos são os recortes que podemos fazer da realidade". Então, por que não o fazer com autoria, autonomia e arte?

Nesse processo, os sujeitos têm a oportunidade de se expressar, de construir novos significados e novos referenciais, de ampliar suas compreensões e de plasmar sua produção artística e suas leituras de mundo (VASCONCELLOS, 2006). Compreendemos que o teatro pode se constituir em ferramenta que aproxima Ciência e Arte, na apreensão de múltiplos objetos de ensino de Ciências. Acreditamos que a "[...] função do teatro seria a de possibilitar encontros capazes de gerar novas formas de pensar, sentir, agir" (ARMILIATO; ARAUJO, 2011, p. 134).

Cachapuz (2014) nos revela que Arte e Ciência podem aprimorar a qualidade da educação e ensejar junto aos professores a ideia de mudança, renovação 
do fazer docente, com o abandono progressivo das meras exposições orais em sala de aula, por acreditar que a relação Arte e Ciência desenvolve uma visão não redutora do conhecimento. Ao pensarmos na proficuidade da interação Ciência e Arte, não podemos deixar de considerar que o "[...] conhecimento científico está longe de ser noção consensual e tranquila" (DEMO, 2010, p. 17); e, nesse contexto, avaliamos que a ciência apresenta por si só um "tom teatral”, pois está impregnada de controvérsias, disputas, argumentação, contra-argumentação, dilemas e conflitos, elementos convenientes à produção teatral.

Compreendemos que favorecer a experiência artística de sujeitos contribui para apreensão do saber com "sabor", emoção, sensibilidade, afetividade e sensação positiva, dentre outros aspectos (OLIVEIRA; STOLTZ, 2010; VASCONCELLOS, 2006). Desse modo, envolve a dimensão sensível do humano e, dentre outros aspectos, colabora para a inserção do ser humano no mundo com qualidade social, justamente na compreensão sensível das múltiplas questões (social, econômica, política, ambiental, ética etc.) que se afiguram na atual sociedade, em intenso processo de transformação.

Apoiamo-nos nas ponderações de Molder (2003 apud MOLDER; HISSA, 2011, p. 246), a saber:

Penso mais a ciência como ciência-saber, diferentemente da técnica e da tecnociência, está à procura de interpretações criativas, de representações, de novos arranjos lidos através da linguagem convincente, clara e que dialoga. [...]. O que penso de ciência a se reinventar, libertando-se da sua inutilidade, se aproximando muito da sua concepção de arte.

É assim que podemos romper com compreensões de uma ciência descontextualizada, desligada da realidade, asséptica, neutra, ingênua, reducionista, características que o campo da arte já superou (MOLDER; HISSA, 2011). Mesmo porque a "[...] ciência não se distancia da interpretação, leitura, representação, criação, fabricação [...] ciência e arte são motivadas por movimentos aproximados" (MOLDER; HISSA, 2011, p. 247).

Entendemos que na interface Ciência e Arte, a leitura do mundo permite ao sujeito tomar consciência do lugar onde está inserido, ao mesmo tempo em que este o percebe em suas múltiplas dimensões, antes impregnado, unicamente, pela racionalidade tecnocientífica, o que certamente obstaculiza a visão complexa do ser humano e do mundo. Ao considerarmos todas as dimensões que conformam o mundo e a nós mesmos, há a possibilidade de (re)encontro com 
realidades valiosas da constituição dos seres humanos e do próprio mundo, sob uma ótica mais humanizadora e sensível.

Compreendemos que a " [...] arte, como as demais formas simbólicas, é uma modalidade de simbolização com a qual o homem constrói sua realidade, engendrando conhecimento com suas próprias perspectivas e valores" (FURLANETTO, 2012, p. 36). Ao mesmo tempo, concebe novas/outras leituras, com possibilidade de conferir visibilidade aos aspectos antes inquestionáveis de estar e atuar no mundo. Então, com esses argumentos, nos contrapomos à ideia mitificada de que a arte pertence ao campo das subjetividades e a ciência como inerente ao campo da racionalidade.

Vasconcellos (2006, p. 35) avalia a importância do teatro "[...] como instrumento de socialização, politização e educação". E, ainda, afirma que a “[...] arte é um fenômeno comum a todas as culturas, desde as mais primitivas às mais civilizadas, desde as mais antigas às mais atuais" (VASCONCELLOS, 2006, p. 40-41). O teatro, desde a Grécia Antiga, adentrou diferentes campos societários, tais como religião, política, cultura, educação, dentre outros (MAREGA, 2011). Assim, o desenvolvimento do teatro apresenta um longo constructo histórico que coincide com a evolução das sociedades.

O paradigma dessa aproximação nos remete ao legado de Leonardo da Vinci. Considerado ícone histórico e à frente de seu tempo; o artista possuía verdadeiro fascínio por diversas áreas de conhecimento, como Arte, Biologia, Matemática e Engenharia, entre outras, e, em sua época, foi um artista que lançou mão dos recursos disponíveis para criar novas formas para observar e registrar o mundo a sua volta (FERRARI, 2012). Segundo, ainda, o referido autor, os desenhos de anatomia de Leonardo da Vinci passaram pelas mãos de médicos e cientistas de vários lugares do mundo que almejavam compreender o funcionamento do corpo humano. Além do seu interesse pela anatomia, o artista realizou diversos estudos sobre animais e plantas.

A ideia em si, de que o teatro pode contribuir para o processo educacional é antiga, e pode ser verificada na Arte poética de Aristóteles, no teatro ocidental, assim como no teatro da Idade Média, que se utilizava da linguagem teatral para ensinar a vida dos santos (LOPES, 2004; GARDAIR, 2012). A igreja realizava seus sacramentos em espetáculos que se disseminaram pela Europa, tornando-se prática muito popular (LOPES, 2004). Concordamos que o teatro, para além do entretenimento, da diversão, "[...] recobre ações reflexivas, formativas e educativas" (MAREGA, 2011, p. 287).

Ao ponderar sobre os processos de ensino e de aprendizagem que "[...] permitam assegurar a formação e o desenvolvimento do ser humano [...]" (MORIN, 2003, p. 8), entendemos que o teatro se configura como elemento valioso para o ensino de Ciências e para a formação de professores. Mas, constitui-se, 
também, em desafio articular a cultura científica e a humanística, o que implica, segundo Morin (2003), em mudança de pensamento. Assim, o uso do teatro e outras expressões artísticas podem contribuir para mudança de pensamento também sobre ensinar e aprender.

Medina (2010) acredita que o desenvolvimento de estratégias educativas que conjuguem Ciência e Arte pode trazer inovações para o ensino de ciências, tanto no ambiente formal das escolas como nos ambientes de ensino não formais, de natureza diversa. Nesse contexto, o teatro pode mostrar contradições da sociedade e seus múltiplos determinantes e, assim, contribuir para um ensino de ciências que envolva o aluno no processo educativo que "[...] valoriza a reflexão, a ação, a curiosidade, o espírito crítico [...] produção de conhecimento com autonomia, com criatividade, com criticidade [...] [com] interpretação do conhecimento e não apenas aceitação" (BEHRENS, 2013, p. 55).

Temos a considerar, com Canda (2010, p. 244), que "[...] a arte traz, em si, um intenso rigor pedagógico por estimular ações de interação social, apuro da percepção e motivação da criação". Entendemos que, no âmbito do ensino de ciências, o teatro pode problematizar e comunicar múltiplas questões implicadas no desenvolvimento da sociedade, afastando-se do modelo tradicional de ensino, impregnado pela visão positivista e mecanicista, recolocando o sujeito como responsável pela sua própria aprendizagem, o que contribui para a constituição de novos/outros significados ao processo de ensino e de aprendizagem.

Por outro lado, no campo da formação de professores, notadamente para o ensino de ciências, nos afiliamos as ponderações de Figueiredo (2015), no sentido de favorecer a constituição de professores-artistas. Para esse autor, a compreensão do que seja professor-artista assim se configura:

O que chamo de professor artista aqui é a capacidade de o professor ser criador no espaço da sala de aula, não deixando esmaecer a chama artística pertencente ao teatro dentro do estabelecimento escolar. Para tanto, é preciso proporcionar um ambiente favorável à aprendizagem do professor-artista (FIGUEIREDO, 2015, p. 141).

Compreendemos que é importante que, nos espaços de formação de professores (inicial e/ou continuada), privilegiemos situações que concorram para estimular o fazer docente na perspectiva de constituição de professoresartistas. Essa funcionalidade docente significa exercer o ensino com criatividade e criticidade, aspectos que podem ser considerados ao fazermos uso do teatro como um instrumento de ensino e de aprendizagem. Para Boal (2013), o teatro 
é algo que existe dentro de nós, em cada ser humano, ou seja, a capacidade de teatralizar é inerente a todo o ser humano - o exercício do teatro pode ser realizado em qualquer lugar, em qualquer situação e por qualquer pessoa. Então, por que não na sala de aula?

\section{Segundo ato: nos caminhos da pesquisa-formação}

A pesquisa configurou-se como qualitativa (MINAYO, 2016) na modalidade narrativa (CLANDININ; CONNELLY, 2011). A investigação qualitativa para os referidos autores tem como objetivo compreender fenômenos em toda a sua complexidade e no seu ambiente natural. Nesse sentido, privilegiamos contato estreito com os sujeitos de pesquisa no ambiente de sala de aula como professora/pesquisadora, para que pudesse compreender os fenômenos de interesse investigativo.

Na pesquisa em pauta, adotamos a pesquisa-formação, uma das dimensões da pesquisa narrativa, na compreensão de que os processos formativos envolvem uma dimensão de conhecimento e quem dele participa é capaz de descrevê-los, seja essa construção individual ou coletiva. Para que as discussões desses processos formativos sejam consideradas significativas, é essencial que os indivíduos busquem se envolver em todos os momentos das atividades por conta própria e que, além disso, sejam capazes de se integrar com os grupos e nas negociações propostas por eles (JOSSO, 2010).

O dispositivo-cenário "pesquisa-formação" é, dessa maneira, qualificado pela autora justamente pelo fato de a pesquisa colaborar para a formação dos participantes do processo. Permite um ambiente em que os indivíduos sejam capazes de construir aprendizagens, tanto reflexivas como interpretativas (JOS$\mathrm{SO}, 2010)$. Por sua vez, a pesquisa narrativa tem sido largamente utilizada em trabalhos que versam sobre a experiência educativa. Sua utilização justifica-se "[...] pelo fato de que nós, seres humanos, somos organismos contadores de histórias, organismos que, individual e socialmente, vivemos vidas relatadas" (CONNELLY; CLANDININ, 1995, p. 11). Nesse sentido, o estudo da narrativa é o estudo da maneira como os seres humanos experimentam o mundo.

A pesquisa ocorreu no contexto do desenvolvimento do tema' "Relações entre Ciência, Sociedade e Cidadania II”, do Curso de Licenciatura Integrada

1 A proposta curricular do curso em que a pesquisa ocorreu está organizada por Eixos Temáticos, Temas e Assuntos, numa perspectiva interdisciplinar, opondo-se à estrutura disciplinar propriamente dita, e ocupa-se com o Letramento Científico, Matemático, Digital e na Língua Materna. 
em Educação em Ciências, Matemática e Linguagens, da Universidade Federal do Pará. A ementa da temática está pautada na educação e cidadania, aspectos históricos dos direitos humanos, educação em direitos humanos, multiculturalismo e educação inclusiva e, ainda, discussões relacionadas à inclusão econômica e ao direito ambiental. A abordagem metodológica empreendida na referida temática deu ênfase à produção de conhecimentos, a partir de experiências com práticas teatrais, no sentido de conformação de espaço de autonomia e de expressão subjetiva.

Recorremos ao teatro jornal como uma das modalidades teatrais, o qual consiste em diversas técnicas simples que permitem a transformação de notícias de jornal ou de qualquer material não dramático em cenas teatrais, o que contribui para a desconstrução e desvelamento do que se lê (BOAL, 2013). A atividade foi construída a partir de uma notícia de um jornal de circulação diária da cidade de Belém, estado do Pará, intitulada "Boca no trombone", do dia 22 de outubro de 2014.

A reportagem versava sobre uma reclamação de moradores de uma rua localizada nas proximidades de um canal que, frequentemente, transbordava em função da grande quantidade de lixo ${ }^{2}$ despejado pelos próprios moradores, atitude associada principalmente à coleta irregular do lixo, à ausência de aparato apropriado para o seu depósito e à falta de sensibilidade ambiental da população, entre outros aspectos. Após a leitura da notícia, os alunos foram convidados a criar um diálogo (para um tempo de encenação de 10 minutos) no contexto de um telejornal simulado. Ao mesmo tempo, foram orientados a ampliar o conteúdo do tema. Sugerimos que no diálogo houvesse a incorporação das causas do aumento da produção de lixo na sociedade, bem como a indicação das possíveis soluções.

Para fins deste trabalho, selecionamos o telejornal intitulado "Diálogo Noturno", cujas narrativas foram submetidas à Análise Textual Discursiva (ATD) nos termos de Moraes e Galiazzi (2011). A ATD pode ser caracterizada como "[...] exercício de produção de metatextos, a partir de um conjunto de textos [denominado corpus]" (MORAES, 2007, p. 89).

Os metatextos são construídos [...] "a partir da inserção no texto de falas e citações de fragmentos dos textos analisados”, e tais inserções são denominadas de interlocuções empíricas (MORAES, 2007, p. 100). No momento da produção dos metatextos, as interlocuções teóricas, que nada mais são do que os diálogos com autores que versam sobre os temas ou fenômenos em foco, também são relevantes para a constituição e validação dos metatextos. Nesse processo, os

2 Termo comumente usado para designar resíduo sólido. 
autores dos textos precisam ver a representação de suas ideias nas construções realizadas nos metatextos (MORAES, 2007).

\section{Terceiro ato: no ar, o telejornal!}

O telejornal "Diálogo Noturno" foi assim nomeado, para referir o turno ao qual pertencem os alunos da licenciatura, passando também a ideia de que o jornal vai ao ar no período da noite. O referido telejornal apresentava o diálogo entre dois jornalistas e um convidado na abordagem do tema lixo. Cabe destacar que a dupla de alunas, autoras do enredo jornalístico, optou por apresentar o telejornal no formato de powerpoint. Assim, os diálogos apresentavam-se em balões, correspondentes a cada personagem do diálogo (Jornalista 1, Jornalista 2 e Especialista). A cada passagem do diálogo, as alunas narravam as falas. Nesse ponto, temos a destacar que o teatro se constitui uma arte própria, mas a ação teatral pode reunir imagens (GUERRA, 2013).

O telejornal inicia-se com um "boa noite" aos telespectadores, de uma das jornalistas (Jornalista 1). Em seguida, a mesma jornalista dá início à reportagem com a seguinte afirmação:

Jornalista 1: A produção do lixo tem sido um tema de grandes debates por ser considerado um dos problemas graves da nossa sociedade.

Note-se que, ao introduzir o tema, a discente já anuncia a gravidade da questão em foco, mas não como um discurso vazio, pois no desenvolvimento do "enredo teatral", como poderemos perceber nas análises subsequentes, para além de uma postura passiva de retratar os contextos societários, tem-se a percepção crítica da realidade. Certamente, estimulando os espectadores (outros discentes) ao pensamento crítico.

Assim, na continuação da reportagem, a Jornalista 2 acrescenta ao diálogo a seguinte informação:

Jornalista 2: O Brasil, até 2013, ocupava a quinta posição entre os que mais produziam lixo no mundo. 
De fato, é nesse caminho que o Brasil tem seguido os países desenvolvidos, em termos de produção de lixo, conforme percebeu a discente ao trazer a estatística que revela a posição brasileira no cenário global. Quando nos referimos ao lixo urbano, nosso país produz em torno de 35 milhões de toneladas por ano, com uma média de 0,7 a $0,8 \mathrm{~kg}$ per capita por dia. A capital da cidade de São Paulo, por exemplo, é a terceira metrópole que mais produz lixo no mundo (12.500 toneladas diárias), perdendo apenas para Tóquio e Nova York (ZUBEN, 2006).

Prosseguindo o diálogo, a Jornalista 1 revela o seguinte:

Jornalista 1: Muito mais que um problema ambiental, implica também em uma questão social.

A percepção da discente quanto ao lixo se constituir numa questão ambiental é atual e preocupante. O lixo pode ser considerado um fato ambiental da modernidade, ao considerarmos as observações de Vieira e Berrios (2003, p. 37), a saber:

O advento [...] que também poder-se-ia denominar Modernidade, é considerado nos diversos estudos teóricos analisados como uma marca importante da intensificação da problemática dos resíduos e do lixo. Dessa época em diante, as quantidades e os volumes dos detritos gerados viram-se contínuas, crescentes e, em muitos casos, gigantescas. A composição e as características tornaram-se diversificadas e difíceis de serem tratadas pela incorporação de novos resíduos cada vez mais estáveis ante a decomposição. Os impactos ambientais que eles originam passaram a constantes.

Então, podemos depreender que a geração e o acúmulo de lixo, na atualidade, configuram-se como um dos problemas ambientais de extrema relevância e gravidade. Mas o lixo é também uma questão social, como destaca a discente, ao considerarmos que a inadequada disposição do lixo confere riscos à saúde humana (campo social).

Na sequência, a Jornalista 2 mostra algumas das consequências trazidas pelo acúmulo de lixo na cidade de Belém, com imagens de locais repletos de lixo. A discente coloca em evidência a banalização do cotidiano, incitando ao estranhamento, dos demais discentes, do que está posto como socialmente 
comum. Então, podemos depreender que, nesse momento, a arte, representada pelo teatro jornal, constitui-se instrumento de denúncia e de crítica da realidade socioambiental impingida à cidade de Belém.

No segundo "bloco" do jornal, as jornalistas trazem um especialista para falar a respeito do problema:

Jornalista 1: Estamos aqui com o geógrafo Gabriel Silva, especialista em problemas urbanos. Boa noite! O lixo se modificou ao longo dos anos. A que o Sr. atribui essas mudanças?

Especialista: Boa noite! Bom, o nosso sistema econômico é o principal fator por essa diferença. Antigamente, a predominância do lixo gerado era orgânico. A partir da Revolução Industrial, a produção, que era em pequenas quantias, somente para a subsistência, passou a ser em larga escala e com produtos em sua maioria descartáveis, ou seja, que são inutilizados em poucas vezes de uso.

De fato, é pertinente afirmar que as transformações pela qual a sociedade vem passando, em decorrência da transição da sociedade agrária para a urbana e industrial, foi acompanhada pelas mudanças no tipo de lixo produzido pela nossa sociedade. Antes da revolução industrial, o lixo produzido era composto de restos e sobras de alimentos, hoje, em função da industrialização de produtos e bens, a nossa sociedade, agora de consumo, passa a descartar grandes quantidades de resíduos (GONÇALVES, 2011; TEIXEIRA, 2004), de origem orgânica e inorgânica.

Observe-se, no trecho acima, referência ao atual sistema econômico (capitalismo), como um fator que configurou o cenário vigente, em relação ao lixo. Então, de certo modo, podemos afirmar que, por meio do teatro jornal, os discentes assumiram, mesmo que timidamente, uma postura de contrariedade ao atual estado de coisas.

Esse fato nos leva a pensar na possibilidade de transformação, a partir da compreensão crítica da realidade, com afastamento do processo alienante que nos faz aceitar scripts falaciosos, como, por exemplo, que só o mercado basto, e suas externalidades, passivos sociais e ambientais, constituem-se produto esporádico. Então, entendemos que a arte, aqui representada pelas práticas teatrais - teatro jornal - é capaz, por exemplo, de desnaturalizar o modus operandi do capital.

Ao considerarmos que o teatro tem a possibilidade de ampliar o potencial da educação, para além dos mecanismos de mera formação técnica e profissional, 
o processo de ensino e de aprendizagem, envolvendo o teatro, pode transformar o aluno, o professor, o espaço da sala de aula, a escola etc. (GUERRA, 2013). A transformação ocorre no sentido de que os educandos tenham a possibilidade de apreender, criticamente, a miríade de questões emergentes do presente momento histórico.

$\mathrm{Na}$ continuidade, a Jornalista 2 aproveita a presença do especialista para obter mais informações:

Jornalista 2: O lixo tem se tornando um dos grandes problemas urbanos. Quais fatores o Sr. atribui para esta preocupação?

Especialista: São muitos [os fatores]. Vão desde a relação de consumo até o descarte desse lixo. Falta o poder público arcar com suas responsabilidades de criar e manter uma logística de recolhimento [...] até a conscientização da população em selecionar seu lixo e descartar em dias e locais apropriados. A cultura do consumo eleva a quantidade dos resíduos e, unindo essa problemática com a falta de eficiência dos serviços de coleta, acaba gerando prejuizos de várias ordens.

Concordamos! Não há dúvidas quanto à existência de vários fatores que tornam o lixo uma preocupação. As discentes nos convidam a refletir sobre a racionalidade que subjaz ao capitalismo, ou seja, cada vez mais somos impelidos para o consumo e, como consequência, evidencia-se a crescente produção de resíduos (REIS, 2012). Note-se que, para além de meros espectadores da realidade socioambiental, os discentes assumiram a condição de atores no/do processo, visto que foram capazes de imprimir, na construção dos seus diálogos, uma abordagem crítico-reflexiva, aproximando arte (teatro) e crítica.

A Jornalista 1 retoma a questão dos prejuízos causados pelo lixo no seguinte diálogo:

Jornalista 1: Quais seriam esses prejuizos?

Especialista: Começa pelo ambiental e vai até a questão da saúde. Ao jogar constantemente lixo nos rios ou córregos, ele vai se acumulando até provocar enchentes, pois não irá permitir o fluxo das águas. Quando 
esse lixo é exposto ao ar livre, atraem roedores e insetos em geral, que disseminam vários tipos de doenças.

É evidente que o acúmulo de lixo no meio ambiente aumentou a poluição do solo, subsolo e das águas, além de comprometer as condições de saúde das pessoas em todo o mundo, particularmente de regiões mais empobrecidas (FERNANDES, 2007). Os problemas ambientais são, ao mesmo tempo, problemas de saúde (CAMPONAGARA; KIRCHHOF; RAMOS, 2006).

Assim, na constituição dos diálogos, as discentes ampliam a realidade posta (reportagem jornalística) para reinterpretá-la à luz de outras referências/ conteúdos. A teatralização de um problema (como, por exemplo, o lixo) permite um distanciamento que favorece aos sujeitos (no caso, os discentes) perceber o que, de fato, está desencadeando a situação e suas consequências.

Na sequência, a jornalista amplia suas indagações, a saber:

Jornalista 1: $O$ Sr. acredita em solução?

Especialista: Sim! A primeira delas começa pela conscientização. Se todos fizessem uma reflexão acerca dos hábitos de consumo, provavelmente desaceleraríamos o avanço das consequências.

Jornalista 1: Desacelerar o Sr. diz... Por que não sanar?

Especialista: Porque alguns efeitos já aconteceram. Por exemplo, o acúmulo de lixo nos leitos dos rios acelera o processo de assoreamento, o que pode provocar comprometimento e até extinção da vida aquática [...].

O trecho final do diálogo entre a Jornalista 1 e o Especialista gira em torno de uma possível solução para o problema do lixo. Em realidade, a maioria dos autores, ao abordar a temática do lixo, refere-se à questão do consumo/ consumismo.

Assim, para Schlindwein (2013, p. 50), “[...] os problemas ambientais são consequências do modo de vida adotado pela sociedade, com maior ou menor grau de influência de acordo com sua capacidade de consumo". De fato, 
o componente balizador da sociedade contemporânea diz respeito ao consumo e, em consequência deste fato, evidenciamos pressões sobre a base de recursos naturais e a produção acentuada de resíduos.

Podemos ponderar que, no trecho final do diálogo entre a Jornalista 1 e o Especialista, evidenciamos proposições plausíveis. Entendemos que tal fato se deu pela capacidade que o teatro tem de invocar o pensamento crítico, colocar questões pertinentes ao cenário societário, abalar o imaginário, em relação ao que é aceito como verdade inquestionável por parte daqueles que se propõem a fazer a leitura crítica do mundo.

$\mathrm{Na}$ finalização do telejornal, as jornalistas agradecem a presença do geógrafo Gabriel Silva e despedem-se dos telespectadores com um "boa noite". Cabe destacar, nesse ponto, que, após a finalização do Telejornal, promovemos uma intensa discussão sobre as questões arroladas na apresentação do tema, inclusive, ampliando seu conteúdo para além dos aspectos constantes na discussão deste artigo.

\section{Quarto ato: o teatro na aproximação entre Ciência e Arte}

Entendemos que o teatro pode potencializar o diálogo entre Ciência e Arte e, ainda, instaurar a racionalidade crítica, a partir de uma situação interativa com o mundo e, principalmente, na sua representação. Nesse contexto, o teatro pode se constituir num "método" de intervenção para a construção do pensamento crítico dos estudantes. Ao mesmo tempo, o teatro possibilita o aprimoramento da nossa capacidade ética e o exercício da razão sensível e, assim, dá lugar à resistência aos racionalismos atualmente vigentes na nossa sociedade. Tais racionalismos obscurecem a apreensão da multidimensionalidade da realidade social e ambiental.

O teatro permite inaugurar um conhecimento próprio, original e autêntico, além de promover realmente transposição não reducionista, dos conhecimentos socialmente relevantes (SANTOS; SCHNETZLER, 1998), cujas articulações, tensões e embricamentos podem conferir a apreensão/construção de novos/outros significados ao/do mundo. Podemos afirmar que na atividade proposta - teatro jornal -, tais pressupostos foram efetivados, pois favorecemos, na intencionalidade educativa e pedagógica, a discussão crítica de um tema, frequentemente destacado pela mídia, notadamente ao se reconhecer a gravidade da problemática na sociedade paraense. 
As discentes, na representação das jornalistas, comunicaram perspectivas, compreensões e informações academicamente pertinentes e críticas, afastando-se de uma mimese irrefletida, inclusive, instigando ao estranhamento do cotidiano, a partir da apreensão crítica da realidade socioambiental do local (cidade de Belém). Assim, a experiência do teatro jornal levou à constituição de espaços de (re)criação, de vivências estéticas, de resgate do modo como se aprende (e como se ensina também), em um processo dialético que favoreceu a compreensão da realidade ambiental.

Entendemos que, no âmbito do ensino de ciências, o teatro se constitui de "lugar" privilegiado de experimentação, de transformação, de renovação e de (re)pensar o mundo. A perspectiva de renovação do ensino de ciências, com o uso da arte pela ciência e a arte como forma de ampliar a compreensão da ciência no mundo, nos leva a ponderar que ao vincularmos pensamento crítico às possiblidades de um fazer criativo, como no teatro, tem-se a constituição de "produtos" que auxiliam o fazer educativo, especialmente no ensino de ciências com a intencionalidade pedagógica de formação de cidadãos críticos.

A partir das análises da produção do telejornal, apresentadas neste artigo, (re)afirmamos que o teatro se constitui materialidade mediadora de recriação constante da cena de sala de aula, e que proporcionou aos estudantes a expressão de um discurso cênico com criticidade, criatividade e sensibilidade, ao experimentarem uma maneira particular de problematizar seus pontos de vista e posicionamentos frente ao tema discutido.

\section{REFERÊNCIAS}

ARMILIATO, V.; ARAUJO, S. C. dos S. O lugar do político no teatro. O Mosaico, Revista de Pesquisa em Artes da Faculdade de Artes do Paraná, Curitiba, n. 5, p. 134-146, 2011.

BEHRENS, M. A. O paradigma emergente e a prática pedagógica. Petrópolis, Rio de Janeiro: Vozes, 2013.

BOAL, A. Teatro do Oprimido e outras poéticas políticas. São Paulo: Cosac Naify, 2013.

CACHAPUZ, A. F. Arte e ciência no ensino das ciências. Interacções, Portugal, n. 31, p. 95-106, 2014.

CAMPONAGARA, S.; KIRCHHOF, A. L. C.; RAMOS, F. R. S. A relação enfermagem e ecologia: abordagens e perspectivas. Revista Enfermagem UERJ, Rio de Janeiro, v. 14, n. 3, p. 398-404, 2006. 
CANDA, C. N. Sentidos da arte: diálogos entre teatro, a experiência estética e a educação. Revista Cientifica da Faculdade de Artes do Paraná, Curitiba, v. 5, p. 243-261, 2010.

CLANDININ, D. J.; CONNELLY, M. F. Pesquisa narrativa: experiência e história em pesquisa qualitativa. Tradução: Grupo de Pesquisa Narrativa e Educação de Professores ILEEI/UFU. Uberlândia: EDUFU, 2011.

CONNELY, F. M.; CLANDININ, D. J. Relatos de experiência e investigação narrativa. In: LARROSA, J. Déjame que te cuente - ensayos sobre narrativa y educación. Barcelona, Laertes, S. A. de Ediciones, 1995. p. 11-59.

DEMO, P. Educação científica. Boletim Técnico SENAC, Revista de Educação Profissional, Rio de Janeiro, v. 36, n. 1, p. 15-25, 2010.

FERNANDES, M. Coleta seletiva de resíduos sólidos urbanos: um estudo da gestão de programas de Florianópolis/SC, Belo Horizonte/MG e Londrina/PR. Dissertação (Mestrado em Administração) - Universidade Vale do Itajaí, Florianópolis. 2007.

FERRARI, S. S. U. Encontros com arte e cultura. 1. ed. São Paulo: FTD, 2012.

FIGUEIREDO, R. C. de. A aprendizagem da docência em teatro através da participação em um projeto de Extensão Universitária. Art Research Journal, Rio Grande do Norte, v. 2, n. 2, p. 138-153, 2015.

FURLANETTO, B. H. A arte como forma simbólica. Revista Cientifica da Faculdade de Artes do Paraná, Curitiba, v. 9, p. 36-50, 2012.

GARDAIR, T. L. C. Integrando a percepção de estudantes à criação de peça teatral: uma alternativa de educação científica em diálogo com as artes. 2012. Tese (Doutorado em Ciências) - Pós-Graduação em Ensino em Biociências e Saúde, Instituto Oswaldo Cruz, Rio de Janeiro. 2012. Disponível em: <https:/www.arca.fiocruz.br/bitstream/ icict/6957/1/DO\%202008\%20-\%20Thelma\%20Lopes\%20Carlos\%20Gardair.pdf>. Acesso em: 27 mar. 2015.

GONÇALVES, P. A cultura do supérfluo: lixo e desperdício na sociedade de consumo. Rio de Janeiro: Garamond, 2011.

GUERRA, E. C. Impressões acerca do pensamento filosófico como contribuição para uma orientação teatral na Educação. Revista Educação, Artes e Inclusão, Florianópolis, v. 8, n. 2, p. 59-78, 2013.

IANNI, O. Variações sobre arte e ciência. Tempo Social, São Paulo, v. 16, n. 1, p. 7-23, 2004.

JOSSO, M.-C. Experiências de vida e formação. 2. ed. Natal: EDUFRN, 2010.

KLISYS, A. Ciência, arte e jogo. São Paulo: Peirópolis, 2010.

LOPES, T. Luz, arte, ciência...ação! In: ARAÚJO-JORGE, T. C. (Org.). Ciência e Arte: encontros e sintonias. Rio de Janeiro: Editora SENAC, 2004. p. 229-249. 
MAREGA, L. M. P. Entre a arte de representar e a arte de ensinar: reflexões sobre teatro e educação. Revista Científica da Faculdade de Artes do Paraná, Curitiba, v. 7, p. 285-296, 2011.

MEDINA, M, O teatro como ferramenta de aprendizagem da física e de problematização da natureza da ciência. Cadernos Brasileiros de Ensino de Física, Santa Catarina, v. 27, n. 2, p. 313-333, 2010.

MINAYO, M. C. O desafio da pesquisa social. In: MINAYO, M. C.; DELANDES, S. F.; GOMES, R. Pesquisa social: teoria, método e criatividade. Petrópolis, Rio de Janeiro: Vozes, 2016. p. 9-28.

MOLDER, M. F.; HISSA, C. E. V. Ciência e arte. In: HISSA, C. E. V. (Org.). Conversações: de artes e de ciências. Belo Horizonte: Editora UFMG, 2011. p. 243-250.

MORAES, R. Mergulhos discursivos: análise textual qualitativa entendida como um processo integrado de aprender e inferir discursos. In: GALIAZZI, M. C.; FREITAS, J. V. de (Org.). Metodologias emergentes de pesquisa em educação ambiental. 2. ed. Ijuí: Unijuí, 2007. p. 85-114.

MORAES, R.; GALIAZZI, M. C. Análise textual discursiva. Ijuí: Unijuí, 2011.

OLIVEIRA, M. E.; STOLTZ, T. Teatro na escola: considerações a partir de Vygotsky. Educar em Revista, Curitiba, n. 36, p. 77-93, 2010.

REIS, A. P. Sujeito e discurso da racionalidade técnica na sociedade mediática. Revista da Associação Nacional dos Programas de Pós-Graduação em Comunicação, E-Compós, Brasília, v. 15, n. 1, p. 1-15, 2012.

REIS, J. C.; GUERRA, A.; BRAGA, M.: Ciência e arte: relações improváveis? História, Ciências, Saúde, Manguinhos, Rio de Janeiro, v. 13 (suplemento), p. 71-87, 2006.

SANTOS, R. R. dos; RIGOLIN, C. D. Diálogos entre ciência e arte sob o enfoque CTS: proposta de uma agenda. In: SIMPÓSIO NACIONAL DE TECNOLOGIA E SOCIEDADE “CIÊNCIA E TECNOLOGIA CONSTRUINDO A IGUALDADE NA DIVERSIDADE”, 4, 2011, Curitiba, Paraná. Anais eletrônicos... Disponível em: $<$ http:// ct.utfpr.edu.br/ocs/index.php/tecsoc/2011/schedConf/Presentations>. Acesso em: 05 ago. 2012.

SANTOS, W.; SCHNETZLER, R. P. Ciência e educação para a cidadania. In: CHASSOT, A.; OLIVEIRA, R. (Org.). Ciência, ética e cultura na educação. São Leopoldo: Editora UNISINOS, 1998. p. 255-270.

SCHLINDWEIN, J. R. O discurso e a prática do gerenciamento de resíduos sólidos urbanos (RSU) em Caxias do Sul/RS. 2013. Dissertação (Mestrado em Geografia) Programa de Pós-Graduação em Geografia, Universidade de Brasília, Brasília. 2013.

SPINELI, P. K.; PINHEIRO, O. J. A fotografia na ciência e na arte: alguns usos e processos. In: SEMINÁRIO INTERNACIONAL DE TECNOLOGIA E SOCIEDADE, 4, 2011. Anais eletrônicos... 2011. Disponível em: <http://www.esocite.org.br/eventos/ 
tecsoc2011/cd-anais/arquivos/pdfs/artigos/gt017-afotografia.pdf>. Acesso em: 26 nov. 2015 .

TEIXEIRA, C. T. Lixo ou rejeitos reaproveitáveis? Revista Eco 21, Rio de Janeiro, edição 87, 2004. Disponível em: <http://www.eco21.com.br/textos/textos.asp?ID=636>. Acesso em: 27 mar. 2015.

VASCONCELLOS, M. A arte entra em cena na escola. In: SILVA, A. C (Org.). Escola com arte: multicaminhos para a transformação. Porto Alegre: Mediação, 2006. p. 35-54.

VIEIRA, E. A.; BERRIOS, M. B. R. G. Lixo: fato ambiental da modernidade. In: GERARDI, L. H. O. Ambientes: estudos de Geografia. Rio Claro: Programa de PósGraduação em Geografia, UNESP; Associação de Geografia Teorética, AGETEO, 2003. p. 37-51.

ZUBEN, V. F. Meio ambiente, cidadania e educação. Caderno do Professor. 5. ed. 2006. Disponível em: <http://www.planetareciclavel.com.br/sala_de_aula/Tetra_Pak/ Cadernos_do_professor.pdf $>$. Acesso em: 30 mar. 2015.

Texto recebido em 20 de agosto de 2017. Texto aprovado em 21 de dezembro de 2017. 